\title{
Innovative Development of New Urbanization under Carbon Lock-in Zhixia Zhou ${ }^{1, \text { a }}$ \\ ${ }^{1}$ Department of Economy and Management, Weifang University, Weifang, China, 262100 \\ awfxyzhouzhixia@126.com
}

Keywords: Innovative development, Carbon lock-in, Low-carbon transform

\begin{abstract}
With development in world economy and surge in population, worldwide climate is facing serious problem, with the low-carbon idea to promote new urbanization is the inevitable requirement for China to go to urbanization and modernization. How to improve the quality and efficiency of urbanization innovative development, to go to intensive, smart, green and low-carbon new urbanization road, is a new and important issue facing China. The thesis analyzed the high-carbon lock-in status in china's new urbanization process, and proposed that, we should co-ordinate the planning, collaborative use initiatives such as scientific planning, industrial structure adjustment and optimization, urban carbon emissions, low-carbon land use and urban adaptive management, to prevent carbon lock-in pattern formation, so as to achieve decoupling innovative development of urbanization and carbon emissions.
\end{abstract}

\section{Introduction}

Nobel economics laureate in, Stiglitz (2001) has predicted: the world's two greatest impacts of the 21st century, are US high-tech industry and China's urbanization. Premier Li Keqiang (2012) pointed out that "China's largest development potentiality in the next few decades lies in the urbanization", which shows the strategic significance of urbanization on economic and social innovative development for China and the world. The Party's 18th Report put forward the strategic task of promoting new urbanization, with particular emphasis on efforts to improve the quality of urbanization. How to improve the quality and efficiency of urbanization, is a new important issue facing China.

In the development concepts, New urbanization puts more emphasis on the overall development, intensive development, low-carbon ecological development, content development and intellectual development. For the innovative development models of new urbanization, scholars from different backgrounds of the subject carried out in-depth study.

\section{High Carbon Lock-in of China's Urbanization Innovative Development}

Contradictions of Innovative Development and Transformation. One of the main sources of high carbon is energy consumption. China's energy production and consumption structure has been dominated by coal for a long time. The proportion of coal in total energy consumption has been hovering around $70 \%$ in the past 20 years. By burning carbon dioxide from fossil fuels with the same calorific value, Coal is $25 \%$ higher than oil, more than $40 \%$ higher than natural gas. A study from Energy Research Institute of National Development and Reform Commission shows that, coal consumptions in Handan, Chuzhou, Yulin, Altay and Haixi account for around 80\% of total primary energy consumption. Data published by"Chinese Academy of Social Sciences - China Meteorological Administration of the Joint Laboratory on Climate Change Economics" shows that, China's urban emissions of carbon dioxide account for $90 \%$ of the country, $98 \%$ of sulfur dioxide emissions. Carbon dioxide emissions by China's 287 prefecture-level cities account for about $72 \%$ of the total emissions, the only $13.3 \%$ municipal area consumed $55 \%$ of social powers. It can be seen that Chinese cities especially urban districts, are regions where energy consumption density is concentrated, while coal-dominated energy consumption structure has become a major obstacle to the innovative development of China's urban. In the process urbanization, how to avoid high carbon development 
model has become a big challenge.

Land Use Change Causes Carbon Emissions. Since the Intergovernmental Panel on Climate Change (IPCC) published the Fourth Assessment Report (AR4) in 2007, the international scientific community has made significant progress in many areas of climate change science, including one achievement: change of land use has led to an increase in carbon dioxide emissions. Urbanization process and accumulation of social wealth require large amounts of land, energy supply and consumption, therefore inevitably accompanied by a large amount of carbon emissions. Carbon emissions caused by land use change is second to fossil fuel combustion of human carbon source, China's urbanization has fast process and large scale, the resulting carbon emissions caused by land-use change will become key factor affecting China's carbon emission reduction targets.

High Carbon Lock-in Developing Model of Urbanization. Over the past few decades, China's urbanization expansion has been a typical extensional model. On the one hand, the urbanization focused on speed rather than quality, urbanization speed did not match the quality. On the other hand, with obvious features of high consumption, high emission, and high expansion, resource allocation had low efficiency, urbanization process had the outstanding problems of huge environment costs. According to estimation of Urban Development and Environment Institute of Chinese Academy of Social Sciences, during "Twelfth Five-Year" period, China enters the dual transformation stage of urbanization and urban development, the average annual urbanization rate increases $0.8 \sim 1$ percentage point and to $55 \%$ in 2015 , and will reach about $60 \%$ by 2020 . In order to meet investment demand, the next 20 years, China's cities will consume $20 \%$ of global energy consumption, and consume up to a quarter of global oil demand growth. Currently, China's own resources and environment is insufficient to support the current high carbon and high emission urbanization development model, meanwhile low-carbon urbanization involves hundreds of industry sectors and thousands of the products, which face problems of both upgrading stock and optimizing adjustment. Therefore, this model once formed, it will be difficult to change in a period of time.

\section{How to Avoid High Carbon Lock-in in Innovative Development of New Urbanization}

How to prevent the formation of high carbon lock-in mode, realize the new-type urbanization and the decoupling development of carbon emissions, is the urgent need of new urbanization in China.

Prevent Formation of High Carbon Lock-in Mode. To prevent the formation of high-carbon lock mode, we should proceed from the following aspects: First, to plan and build urban infrastructure for low carbon innovative development. Second, to establish low-carbon industrial system, develop modern service industries and high-tech industries, improve the technological content and added value of traditional products, vigorously develop the recycling economy. Third, to use new and renewable energy as much as possible, develop distributed energy and promote the integration of urban construction and solar power generation. Fourth, to enhance public awareness and ability to participate in environmental protection, including the voluntary garbage classification, select low carbon travel. Through the joint efforts the public, we try to make avoiding locked in become reality.

Achieve Decoupling Development of New Urbanization and Carbon Emissions. To achieve the decoupling development of new urbanization and carbon emissions, it includes two levels: The first level is relatively decoupling, that is, growth rate of carbon emissions lower than development speed of new urbanization. The second level is absolute decoupling, that is, while maintaining the normal development of new urbanization, to achieve an absolute reduction in carbon emissions. The initial stage of new urbanization innovative development should be aimed at achieving relative decoupling, after developing to a certain stage, be aimed at absolute decoupling transition. 


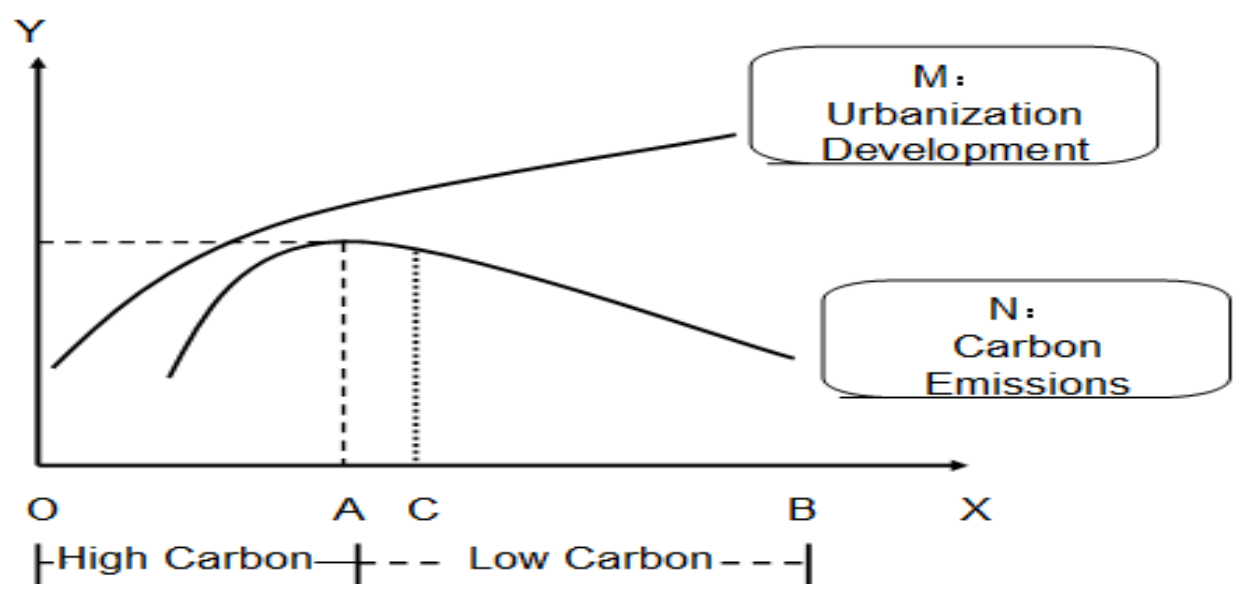

Figure.1. Decoupling development of new urbanization and carbon emissions

As shown in Figure 1, the $\mathrm{X}$-axis represents the innovative development stage of the new urbanization, the Y-axis represents the carbon emission, the curve $\mathrm{M}$ represents the new urbanization innovative development, and the curve $\mathrm{N}$ represents the urban carbon emission. New urbanization first enters the stage of high-carbon innovative development (OA), urban carbon emissions continue to increase, its growth rate even higher than the pace of urbanization, urbanization is built on the basis of high-carbon emissions. With the innovative development of low-carbon, the new urbanization has entered the stage of low-carbon innovative development $(\mathrm{AB})$. At this time, the growth rate of carbon emission is lower than that of urbanization, the urbanization and carbon emissions have realized relatively decoupling (AC). With continuous optimization of low carbon measures, carbon emissions curve will lead to inflection (C), carbon emissions begin to decline absolutely, new urbanization and carbon emissions can really achieve absolute decoupling (CB).

\section{Low-carbon Innovative Path of New Urbanization}

To achieve the low-carbon innovative development of new urbanization, the core is to prevent the formation of high-carbon lock mode, and strive to achieve decoupling development of new urbanization and carbon emissions. In the specific implementation process, it should make scientific low-carbon town planning as the premise, low-carbon industrial restructuring and optimization as the support, urban carbon emission reduction as the key, low-carbon land use as the protection, and urban adaptive management as the basis(shown as Fig.2), with various measures organic coordination, to produce synergies.

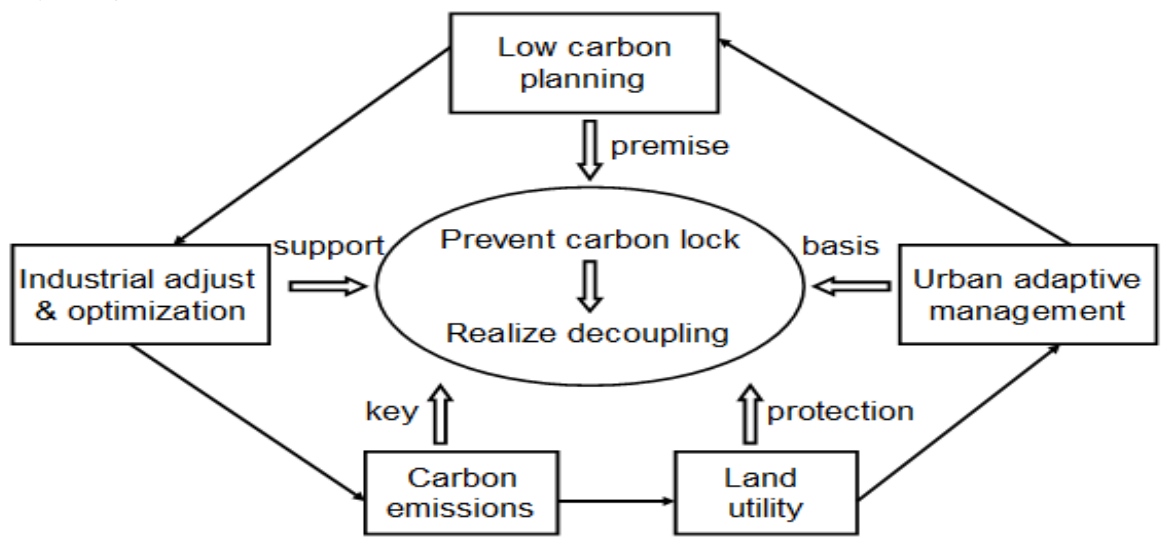

Figure.2. Low carbon innovative path of new urbanization

Make Low-Carbon Development Plan of Urbanization. To promote low-carbon urbanization, it is necessary to scientifically make low-carbon urbanization innovative development planning, rational distribution, and promote the coordinated innovative development of towns, and give full play to the supporting role of industry, to enhance urban low-carbon competitiveness. Through the construction of 
low-carbon demonstration communities, to build low-carbon town, to cope with climate change challenges, so as to build a beautiful China.

Low-Carbon Industrial Restructuring and Optimization. In future innovative development process, the core is to establish a low-carbon industrial system. Industry is the basis of urbanization, we should emphasize the adjustment and optimization of industrial structure, at the same time of improving human development and carbon productivity, control per capita $\mathrm{CO}_{2}$ emissions increase, so that the economic growth mode can transit to green low carbon. While improving low energy consumption, low pollution and low emissions, maintain high output, high level of economic development and high quality of life level, which is development concept of low-carbon urbanization.

Promote Urban Carbon Emissions Actively. China is in the middle of urbanization, we must introduce a new model to build low-carbon town. In the issue of carbon emission reduction, China still has a larger operating space. According to the "Green Paper on Climate Change: Responding to Climate Change Report (2013)", the potential for $\mathrm{CO}_{2}$ reduction in China's cities by 2020 is estimated to be 1.7 billion tons, with industrial, construction and transport sectors accounting for $62 \%$, $24 \%$ and $14 \%$ respectively. China's cities should apply a variety of energy-saving emission reduction technologies, to achieve the goal of reducing carbon dioxide emissions.

Explore New Land Use Patterns. In order to build a low-carbon town and promote the harmonious coexistence of urban innovative development and environmental protection, the town should explore its low-carbon land use modes and countermeasures, in terms of land use optimization, ecosystem carbon sequestration and low carbon economy, so as to realize the sustainable innovative development of towns.

Establish Urban Adaptive Management Model. To promote low-carbon urbanization, in urban governance and planning and design, it is necessary to collaborative consider greenhouse gas emission reduction and respond to climate change-related risks and disasters of different needs, change traditional urban management and governance concepts, make adaptive management, and build Low carbon towns. The establishment of urban adaptive management requires the establishment of policy support mechanisms, including increased R \& D investment in low-carbon and adaptive technologies, taxation and credit support for enterprises, incorporation of key indicators of low-carbon towns into urban planning, government and performance evaluation indicators.

\section{Conclusion}

With development of world economy and rapid increase of population, the world climate is facing serious problems. It is a necessary requirement for China to follow the road of urbanization and modernization by promoting the new urbanization with the concept of low carbon. China's new urbanization in the process of low-carbon development, should coordinately use scientific planning, industrial restructuring and optimization, urban carbon emission reduction, low-carbon land use, urban adaptive management and other initiatives to prevent high-carbon lock mode of urbanization, try to achieve decoupling development of new type of urbanization and carbon emissions.

\section{Acknowledgment}

This thesis is founded by Shandong Province Human \& Social Science Program (17-ND-JJ-15), Shandong Province Natural Science Foundation Program (ZR2014GL010), National Spark Program (2013GA740012) and Shandong Spark Program (2012XH06033), hereby express acknowledgments to them.

\section{References}

[1] D. Cheryl, M. Morris. How does gender affect the adoption of agricultural innovations? The case of improved maize technology in Ghana [J]. Agricultural economy, 2001(9)27-39. 
[2]R.Gershon, R.Slade. The role of public policy in diffusion of improved technology[J].American Journal of Agricultural Economics,1985(5)423-428.

[3] R.Ariel,D. Yaron. Influence of quality and scarcity of inputs on the adoption of modern irrigation technologies[J].Western Journal of Agricultural Economics, 1999(3)224 -233.

[4] J. Foltz. The economics of water-conserving technology adoption in Tunisia: an empirical estimation of farmer technology choice[J].Economic Development and Cultural Change,2003(1), 359-373.

[5] N. Rahelizatovo, J. Gillespie.The adoption of best-management practices by Louisiana dairy produces[J].Journal of Agriculture Application Economics, 2004(1)229-240.

[6] T. Isgin, A. Bilgic, D. Forster.Using count data models to determine the factors affecting farmers' quantity decisions of precision farming technology adoption[J].Computers and Electronics in Agriculture,2008(2)231-242.

[7] J. Mariano, R. Villant, E. Fleming.Factors influencing farmers' adoption of modern rice technologies and good management practices in the Philippines[J].Agricultural Systems,2012(6) 41-53.

[8] Fei Mao, Xiangzhi Kong.Household pesticide safety optional behavior factors-a survey of five major apple producing counties in Shaanxi [J].agricultural economy,2011(3)4-12.

[9] Genxing Pan, Min Gao.Effect of climate change on agricultural production in China[J]. Agricultural Environmental Science, 2011(9): 1698-1706.

[10] Qiguo Zhao, Zengqiang Duan.China’s ecological agriculture development model and its technology system[J]. Soil Sinica, 2010(6)1249-1254.

[11] Fuyan Ke, Maowei Huang.Low-carbon technologies and agricultural development support system[J].Zhejiang Agricultural Sciences,2012(4)727-732.

[12] HongjingShi.Study mechanism of agriculture technology adoption behaviors[J].Fujian Agriculture and Forestry University Journal, 2014(10)29-34. 